\title{
Evaluating impulse purchases generated by affections and advertisement effectiveness
}

\author{
Aakash Kamble ${ }^{a^{*}}$, Aatish Zagade ${ }^{\mathrm{b}}$ and Nayna Abhang
}

${ }^{a}$ Assistant Professor, Indira Global Business School, Pune - 410506, India

${ }^{b}$ Product Data Coordinator, Medline Industries Pvt. Ltd., Bhalerao Towers, Shivajinagar, Pune - 411005, India

\section{H R O N I C L E}

\section{Article history:}

Received: February 1, 2017

Received in revised format: July

6, 2017

Accepted: July 24, 2017

Available online:

July 24, 2017

Keywords:

Dual mediation hypothesis

Celebrity endorsements

Ad effectiveness

Brand affections

Consumer behavior

\section{A B S T R A C T}

Impulse buying occurs when a consumer experiences a sudden, often powerful and persistent urge to buy something immediately. This on-going research considers the affections generated by consumers towards the chocolate brand which is endorsed by a celebrity. The Dual Mediation Hypothesis Model (DMH) is used to ascertain the ad effectiveness of the product/ brand, in this research advertisement featuring the celebrity. The affections generated by the ad leads to generation of affection towards the brand leading to purchase a product/ brand. The chocolate brand selected for the research has high market share and manufactures chocolate based products catering to all classes of consumers. The research primarily focuses on the significance of affections generated by the advertisement for the product. The purchase decision for such products is usually based on consumer impulses and attitudes towards the product/ brand. A convenience sample of 116 individuals was considered for the research and the survey was done using questionnaire method. The findings from the analysis revealed that the consumers purchased the products due to the impulses and affections generated by the ad and brand. There was no clear linkage between the celebrity and brand which lead to purchase intentions of the product/ brand. The Dual Mediation Model was found to be applicable as the affections towards the brand and the ad resulted in purchase intention.

\section{Introduction}

Over the years it has been presumed that endorsing products and services by celebrities yield better results in terms of increase in sales volume thus resulting in the better profits. Little or no thought is given to fact that the products or services endorsed by the celebrities are from various categories altogether. A celebrity who endorses varied products and services across different product lines and sectors usually ends up over-doing the act. Products and services with low investments are usually purchased on impulses of consumers, whereas the products and services having considerable high investment are subjected to rational buying behavior. There is a difference between the behaviors exhibited by the consumers in both these scenarios (Cohen \& Areni, 1991).

The advertisements for the products which are purchased on consumer impulses play a role of generating awareness about the same. For the research, a renowned chocolate bar manufacturing company

* Corresponding author. Mobile No. +919975588200

E-mail address: kamble.aakash@outlook.com (A. Kamble) 
and their specific brand was considered. The advertisement of this brand of chocolate bars features a well-known celebrity from the Indian film industry. The brand has a high market share in Indian market and is also the market leader. With its neatly positioned advertising effort and the endorsements done by the celebrity, this product has been a leader for many years on a consecutive basis.

Dual Mediation Hypothesis Model (DMH) postulates that the affective attitudes towards the brand leads to Purchase Intention (PI) when the effort is low from consumer (Kamble, 2014). In this research, the DMH model is tested to find its applicability in the above mentioned situation. The research studied the samples who were exposed to the advert which was considered for the research and also were familiar with the celebrity in that advertisement. Based on the responses received from the sample the research ascertains the effectiveness of the advertisement and the purchases triggered by it. This research being a part of an on-going research, the findings from it are mentioned in the subsequent headings.

To summarize, the objective of this research is to evaluate the impulse purchases by consumers and the factors behind the same which primarily being the affections generated towards the advertisement and/or the celebrity and the overall effectiveness of the advertisement in communicating the message to the consumers. To ascertain this survey, 116 samples and the analysis of the same was done to substantiate the claim. Existing literature on impulse purchasing behavior and DMH model is reviewed in the research. In the subsequent sections, hypotheses are formulated and the evaluation impulse purchases tested and the implication of the research are discussed.

\section{Literature review}

For last half of the century, consumer researchers have invested their efforts to form a better definition of impulse buying. Early studies on impulse buying stemmed from managerial and retailer interests. Research here placed its emphasis on the taxonomic approach of classifying products into impulse and non-impulse items in order to facilitate marketing strategies such as point-of-purchase advertising, merchandising, or in-store promotions. However, local market conditions, systems of exchange and various cultural forces impact how consumers operate on impulse.

\subsection{Impulse Buying Behavior}

\subsubsection{Nature of Impulse Buying}

In impulse buying the purchase is made primarily without evaluating in great detail. Individuals buying impulse is less likely to consider the consequences or to think carefully before making the purchase (Rook, 1987). The person's attention is concentrated on the immediate gratification of responding to the urge to purchase rather than on solving a pre-existing problem or on finding an item to fill a predetermined need (Barratt, 1985; Rook, 1987). Finally, consistent with general impulsiveness, impulsive buying is immediate (Barratt, 1985; Rook, 1987).

\subsubsection{Impulse Buying Behavior}

Subsequent to 1982, when researchers started paying more attention to impulse buying behavior, researchers started to analyze the behavioral dimensions of impulse buying. Most recently, researchers appear to agree that impulse buying involves a hedonic or affective component (Cobb \& Hoyer, 1986; Piron, 1991; Rook, 1987; Rook \& Fisher, 1995; Weinberg \& Gottwald, 1982). For instance, Rook (1987) reports accounts by consumers who felt the product 'calling' them, almost demanding they purchase it. This emphasis on the behavioral elements of impulse buying led to the definition of impulse as follows. Impulse buying happens when a consumer experiences a sudden, often powerful and persistent urge to buy something immediately (Kamble, 2014). The impulse to buy is hedonically complex and may stimulate emotional conflict. Also, impulse buying is prone to happen with diminished regard for its consequences (Rook, 1987, p. 191). Rook and Hock (1983) identified five crucial elements in 
impulse buying: the onset of psychological conflict and struggle, a reduction in cognitive evaluation, a sudden and spontaneous desire to act, a state of psychological disequilibrium, and a lack of regard for the consequences of impulse buying. Weinberg and Gottwald (1982), cited that, shopper with impulsive buying tendencies normally view an impulse purchase as negative and successfully resist the temptation, at other times they are also more likely to rationalize the negative feelings and make the purchase anyway. This indicates that, although impulsive shoppers may deliberate about the purchase on a cognitive level, at some point in the decision making process the shopper's affective state overcomes their cognitive willpower (Kamble, 2014). These findings support a study, which concluded that, although cognitive deliberation plays a part in the impulse buyer's decision, its influence is smaller than that of the affective state (Weinberg \& Gottwald, 1982).

\subsection{Dual Mediation Hypothesis Model}

Fill (2006) defined marketing communications as a management process through which an organization seeks to engage with its various audiences, in order to (re)position the organization and its offerings in the minds of particular audiences, and in doing so encourage the development of relationships that are of mutual value. The amount of resources dedicated to communication initiatives has meant that companies and managers worry about how to assess whether outcomes coincide with results (Kamble, 2014). Several attempts, based on the relevance of communication effectiveness, have been made to describe how such communication activities work, leading to different frameworks (Vakratsas \& Ambler, 1999) such as cognitive information models (Bharadwaj et al., 1993), pure affect models (Aaker et al., 1986; Blaney, 1986) and the Elaboration Likelihood Model (Petty \& Cacioppo, 1981).

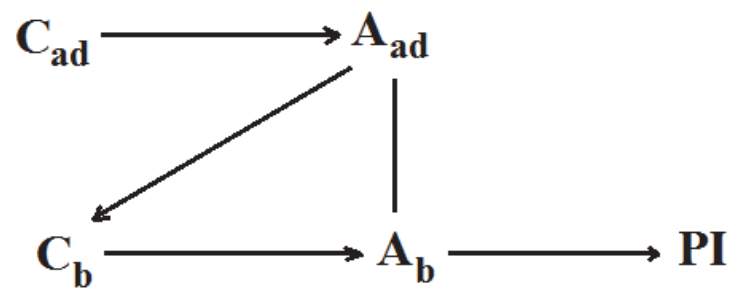

Fig. 1. Dual Mediation Hypothesis Model of Ad Processing

Here $\mathrm{C}_{\mathrm{ad}}$, Aad, $\mathrm{C}_{\mathrm{b}}, \mathrm{A}_{\mathrm{b}}$ and PI represent Advertising cognition, Attitude towards advertising, Brand cognition, Attitude towards brand and Purchase intention, respectively. In line with this, MacKenzie et al. (1986) published a seminal paper in which they explained and tested four alternative models of communication effectiveness. Their primary aim was to find out how attitude towards the ad $\left(\mathrm{A}_{\mathrm{ad}}\right)$ mediates attitude towards the brand $\left(\mathrm{A}_{\mathrm{b}}\right)$ and Purchase Intention (PI), with these three variables representing communication effectiveness. The four models thus analyzed were: the Affect Transfer Hypothesis, the Reciprocal Mediation Hypothesis, the Independent Influences Hypothesis and the Dual Mediation Hypothesis. In the research, the competing explanations share three common paths, namely, ad cognitions $\rightarrow A_{a d}$, brand cognitions $\rightarrow A_{b}$ and $A_{b} \rightarrow$ PI. Cognitions are any thought that comes out during the elaboration of the information, measured using a written protocol known as thought elicitation (Meyers-Levy \& Malaviya, 1999; Sicilia et al., 2005). The Affect Transfer Hypothesis (ATH) proposes a path from $\mathrm{A}_{\mathrm{ad}}$ to $\mathrm{A}_{\mathrm{b}}$, which represents the peripheral route to persuasion in the Elaboration Likelihood Model (Petty \& Cacioppo, 1996). The positive affect generated by the ad is transferred to the evaluation of the product/brand itself without further scrutiny of the information provided (Mitchell \& Olson 1981). The Reciprocal Mediation Hypothesis (RMH) assumes a reciprocal causal relationship between $\mathrm{A}_{\mathrm{ad}}$ and $\mathrm{A}_{\mathrm{b}}$. The idea that people attempt to maintain "balanced" cognitive relationships backs up this point of view (Heider, 1946). The Independent Influences Hypothesis (IIH) posits that $A_{a d}$ and $A_{b}$ exert an independent influence on PI. Finally, the Dual Mediation Hypothesis (DMH) specifies an indirect flow of causation from $A_{a d}$ to $A_{b}$ through brand cognitions $\left(C_{b}\right)$, in addition to the direct influence that links both types of attitude. Compared with the other three alternative models, the 
DMH (Fig. 1) turned out to be the one that best explained ad effectiveness. This implies that $\mathrm{A}_{\mathrm{ad}}$ positively influences $A_{b}$, which lends further support to the idea that $A_{a d}$ is an important mediator of brand attitude formation (Park \& Young, 1984). Additionally, $\mathrm{A}_{\mathrm{ad}}$ exerts a positive influence on brand cognitions, which means that not only the peripheral route plays a role in communication models but so does the central route of persuasion through its effect on cognitions (Petty \& Cacioppo, 1981). The $\mathrm{DMH}$ is still considered one of the most widely accepted models of communication effects to date. Later research supported this perspective and confirmed the appropriateness of the DMH in analysing communication effectiveness (Brown \& Stayman, 1992). The DMH remains to be considered the most widely accepted model of advertising effects hitherto.

Allen et al. (2005), although admitting that finding ways and means to incorporate emotional experience into consumer and market research has been an ongoing challenge for a long time, have carried out some research offline which features that emotional information may serve as a separate antecedent of attitude. That means that emotional reports will add to traditional cognitive information in explaining attitude's variance. However, the cognitive approach has dominated persuasion research whereas the affective processes have been given a relatively minor role in spite of the wide use of emotional appeals in advertising (Morris et al., 2002). Focusing only on cognitive processes and refusing to consider the role of emotions in communication could lead to a misunderstanding of various consumer behaviours.

\section{Materials and methods}

\subsection{Hypothesis Development}

Traditionally, most studies have treated product/brand attitude as a one-dimensional construct (Kamble, 2014). The assertion that attitudes are complex and multidimensional has led some researchers to try to integrate an experiential view of consumption with more traditional functional approaches (Mano \& Oliver, 1993). The earliest exercise to measure the multiple dimensions of product/brand attitudes was that of Batra and Ahtola (1991), who stated that "consumers purchase goods and services and perform consumption behaviors for two basic reasons: (1) consummatory affective gratification (from sensory attributes) and (2) instrumental, utilitarian reasons". In short, consumption "involves experiential as well as instrumental outcomes" (Babin et al., 1994). The first is a hedonic dimension resulting from sensations derived from the experience of using products, and the second is a utilitarian dimension derived from functions performed by products (Voss et al., 2003). The domains, which evidence a fundamental presence across consumption literature, are meant to be neither exhaustive nor mutually exclusive (Babin et al., 1994). Capturing both dimensions with a reliable and valid scale turns out to be a difficult task (Kamble, 2014). Recently, Voss et al. (2003) developed a valid, reliable, and generalizable scale to measure the hedonic and utilitarian dimensions of consumers' attitude. They tested the scale for the central route of persuasion, using involvement as a proxy for cognitive elaboration. In the research, a global model is tested in which emotions and cognitions are used as antecedents of the hedonic and utilitarian dimensions of attitude towards the product/ brand, i.e., by testing the Dual Mediation Hypothesis model. Therefore, the same model is incorporated in the form of cognitive and emotional components that have traditionally been considered fundamental in communication effectiveness (Sicilia et al., 2005; Kempf \& Smith, 1998; Burke \& Edell, 1989).

\section{$\boldsymbol{H}_{0}$ - Impulse purchases are not result of affections}

This is the null hypothesis which is presumed to be true. The impulse purchases made by the consumers of the product used for the research are not a result of the affections generated by the consumers towards the same due to its advertisement. This is the explanation for the null hypothesis which needs to be tested for its validity.

\section{$\boldsymbol{H}_{1}-$ Affections towards the brand will result into purchase intention.}


Affections will be generated towards the brand and the same will result into purchase intention of the same. This will be caused due the sudden need or urge for the purchase of the product leading to impulse buying behavior.

$\boldsymbol{H}_{2}-$ Featuring celebrity in the ad leads to impulse purchases.

This proposed hypothesis is that featuring a celebrity in the advertisement of the product will lead to impulse purchases and increase in sales volume.

\subsubsection{Methodology}

The research employed a convenience sample and was descriptive in design. The sample consisted of individual who were aware of the brand used for the research and the television advertisement for the same. We took individual from a pre-defined area as samples for the survey. Based upon the purpose of the study a total of 150 samples were surveyed and usable data was recovered from 116 questionnaires filled by the respondents. The rest of the data was discarded due to incomplete form of it. Therefore, the effective sample size used for this research was 116. Firstly, they answered questions related to their demographics which are described below in Fig. 2.

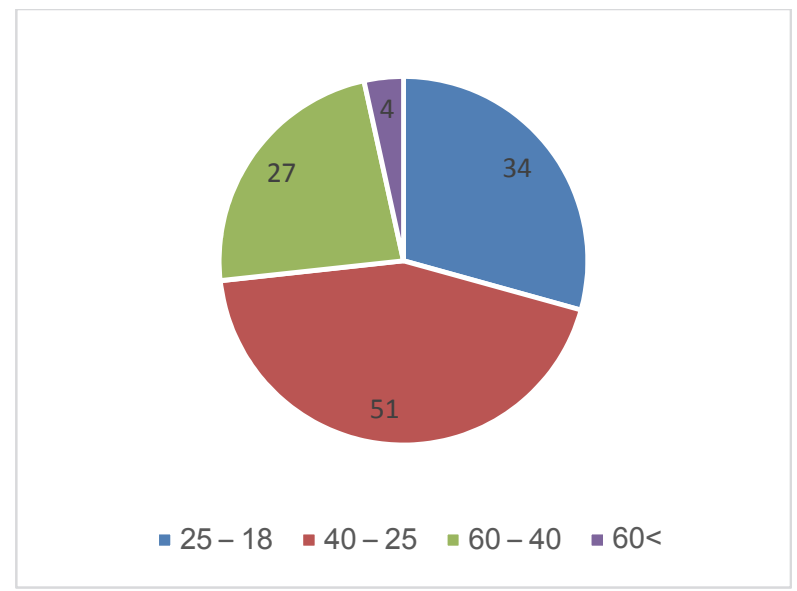

Age

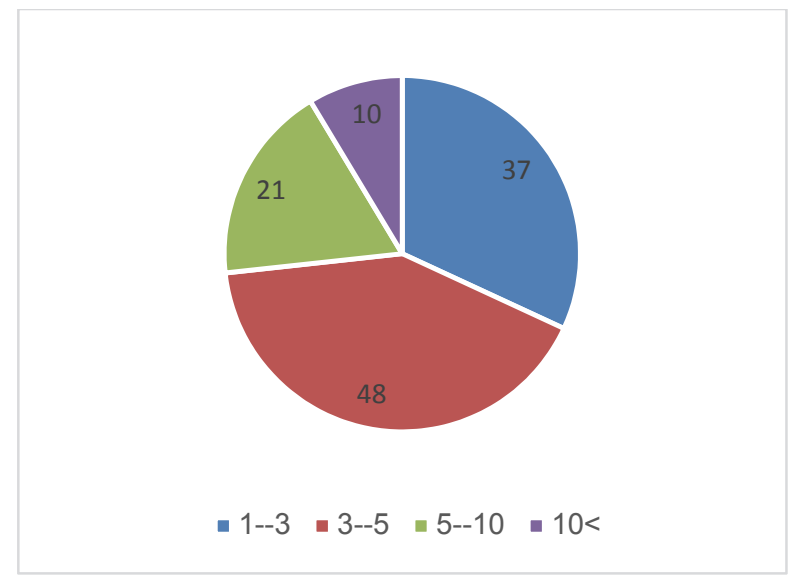

Income per annum (In million Indian Rupees)

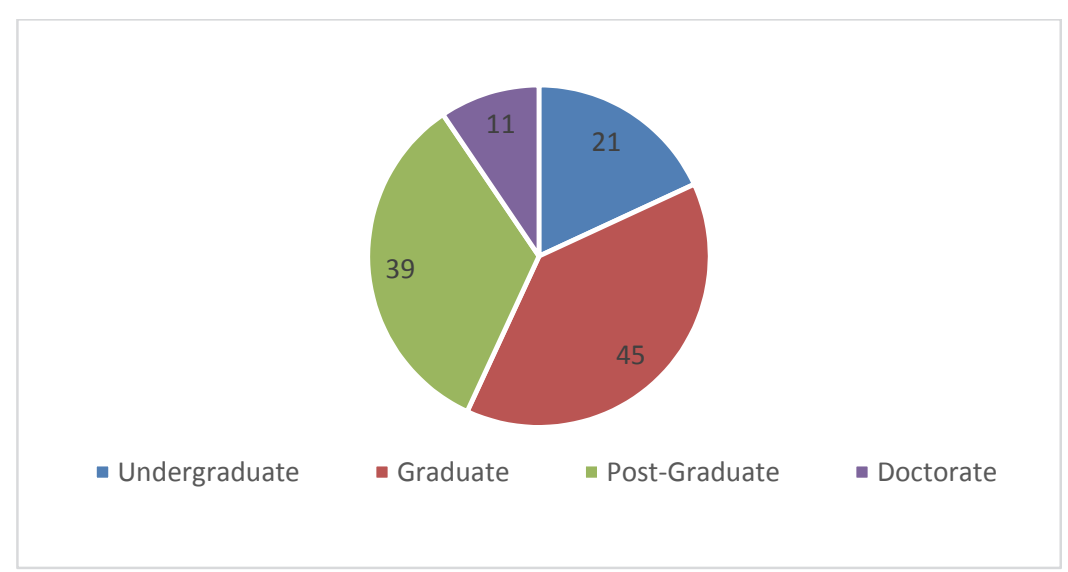

Education

Fig. 2. Personal characteristics of the participants

At first the respondents' product involvement (Zaichkowsky, 1990) questions were asked followed by product knowledge (Smith \& Park, 1992). Although, no previous hypotheses regarding these variables were present, it was decided to include them for controlling the external influences on the analysis. 
Close ended questions related to affections towards the celebrity and purchase intentions and Likert Scale questions were asked to the respondents based on a 5-point Likert Scale. Firstly product involvement and product knowledge questions were asked followed by the affections generated towards the brand and celebrity resulting into impulse purchases. The personality and the image of brand and celebrity's image were then taken into consideration. The last set of questions were related to the Purchase Intention (PI) and the actual purchase of the product. The responses given by the samples were then analyzed and the following interpretations were made from the same.

\section{Results}

\subsection{Hypothesis Testing}

\subsubsection{One Sample t-test}

Based on the analysis we compute that the null hypothesis $\mathrm{H}_{0}$ isn't true. This is further validated by the $\mathrm{t}$ - test carried out on the data. The null hypothesis was based on 2 variables 1 . Brand Affections and 2 . Preference of brand. Table 1 and Table 2 summarize the results of One-Sample t-test.

Table 1

One- Sample t-test Statistics

\begin{tabular}{lllll}
\hline & $\mathrm{N}$ & Mean & Std. Deviation & Std. Error Mean \\
\hline Brand Affections & 116 & 1.2069 & .40684 & .03777 \\
Preference & 116 & 1.9828 & .84424 & .07839 \\
\hline
\end{tabular}

\section{Table 2}

One-Sample t-test

\begin{tabular}{|c|c|c|c|}
\hline Test Value $=1$ & & Brand Affections & Preference \\
\hline $\mathrm{t}$ & & 5.477 & 12.537 \\
\hline df & & 115 & 115 \\
\hline Sig. (2- tailed) & & .000 & .000 \\
\hline Mean Difference & & .20690 & .98276 \\
\hline \multirow{2}{*}{$95 \%$ Confidence Interval of the Difference } & Lower & .1321 & .8275 \\
\hline & Upper & .2817 & 1.1380 \\
\hline
\end{tabular}

Here the test value was taken as 1, and from the One-sample Test we calculated the Significance (2tailed $)=0.000$. There is no method to calculate 1 -tailed significance. Critical value tables were used to calculate 1- tailed significance for $\mathrm{df}=115$. From the results we can deduce that the Significance (1tailed) is also less than test value. Hence we reject the null Hypothesis $\mathrm{H}_{0}$.

\subsubsection{Affections towards brand}

A t- test failed to reveal a statistically reliable difference between the mean number of affections towards brand that the $\mathrm{N}=116$ has $(\mathrm{M}=1.2069, \mathrm{~s}=1.2069)$ and $1, \mathrm{t}(115)=5.477, \mathrm{p}<0.05, \alpha=0.05$.

\subsubsection{Brand preference}

A t- test failed to reveal a statistically reliable difference between the mean number of brand preference that the $\mathrm{N}=115$ has $(\mathrm{M}=1.9828, \mathrm{~s}=1.9828)$ and $1, \mathrm{t}(115)=12.537, \mathrm{p}<0.05, \alpha=0.05$.

Hence, based upon the above results, the significance $<0.05$ in both the cases mentioned above. Hence the null hypothesis is discarded.

\section{Discussions}

$50 \%$ of the respondents said that they purchased any brand of chocolate if their preferred brand isn't available. The sudden urge of consuming chocolate was so intense, that the brand preference was overlooked by the respondents. The notion of impulse purchases was reinforced by the fact that $67.24 \%$ of 
the respondents agreed to the statement that, they do not give much of a thought before purchasing chocolate bar. The preferred brand, if available, will be purchased else the respondents purchased any other brand of chocolate bar. The high market share of the chocolate bar was confirmed by the percentage of respondents purchasing it on impulses. Nearly $80 \%$ of the respondents preferred the brand of chocolate bar when they urged for a chocolate bar. Due to the affections towards the celebrity endorsing the brand, the respondents were inclined towards the affections generated by the ad towards the brand. $80 \%$ of the respondents agreed that, they had strong affections towards the celebrity in the advertisement. A contradicting view was given by the respondents when they were asked that, the affections towards the celebrity and his/ her influence in purchase decision. $80 \%$ of respondents did not agree to the statement. The respondents said that, the presence of celebrity did not influence their purchase decision, and the purchases were made purely on impulses. The respondents were insensitive towards the quantity, price and flavor of the chocolate bar. 54\% of the respondents agreed that, they would purchase the chocolate bar of any quantity, price and flavor to satisfy their urge for the same. The ad effectiveness of the brand was mainly due to the affections towards the ad featuring the celebrity and due to the affections towards the brand. $64.65 \%$ of the respondents agreed that the ad was effective and helped them in finalizing the brand of chocolate bar.

From the analysis of the Likert Scale, few contradicting findings were deduced. The respondents showed strong affections towards the brand, but they overlooked the brand preference in case for strong urge for chocolate bar. Such erratic purchase pattern is usually seen in impulse purchases. Impulse buying behavior occurs when the consumers have strong persistent urge for a particular product, in this case chocolate bar. The linking of DMH to impulse purchases is justified by the purchases due to the ad effectiveness. But in this research, the celebrity endorsing the advertisements generated strong affections towards himself and the advertisement. But the purchase patterns were based on the urges of consumers. If the brand of chocolate bar wasn't available, the respondents purchased competitor's product. So it can be concluded that, the celebrity though creating strong affections, wasn't able to influence the purchase decision. The impulse buying behavior of the consumers was the prime reason for sales of the brand of chocolate.

\section{Conclusion}

The study was designed to evaluate the impulse purchases generated by the affections towards the product and the ad effectiveness of the same. The developments included the notions that the affections towards the brand and ad do result into purchase intention (PI) for the products/ brands. In the research it was found that affections towards the celebrity overshadowed the brand. The consumers would have purchased the product even if the ad did not feature any celebrity. The purchases were random in nature and were not fixed to the chocolate bar brand in the research. The consumers were ready to switch the brand in-case the preferred brand is not available. This was substantiated by the analysis of the survey. From all the above analysis it was found out that impulse buying behavior is not influenced by the celebrity, but the advertisements of such products are effective and lead to purchases.

\section{References}

Allen, C. T., Machleit, K. A., Kleine, S. S., \& Notani, A. S. (2005). A place for emotion in attitude models. Journal of Business Research, 58(4), 494-499.

Babin, B. J., Darden, W. R., \& Griffin, M. (1994). Work and/or fun: measuring hedonic and utilitarian shopping value. Journal of Consumer Research, 20(4), 644-656.

Batra, R., \& Ahtola, O. T. (1991). Measuring the hedonic and utilitarian sources of consumer attitudes. Marketing Letters, 2(2), 159-170.

Barratt, E. S. (1985). Impulsiveness subtraits: Arousal and information processing. Motivation, Emotion, and Personality, 5, 137-146.

Bharadwaj, S. G., Varadarajan, P. R., \& Fahy, J. (1993). Sustainable competitive advantage in service industries: a conceptual model and research propositions. The Journal of Marketing, 83-99. 
Blaney, P. H. (1986). Affect and memory: a review. Psychological Bulletin, 99(2), 229.

Brown, S. P., \& Stayman, D. M. (1992). Antecedents and consequences of attitude toward the ad: A meta-analysis. Journal of consumer research, 19(1), 34-51.

Burke, M. C., \& Edell. J., (1989). The impact of feelings on ad-based affect and cognition. Journal of Consumer Research, 26, 6-83.

Cobb, C. J., \& Hoyer, W. D. (1986). Planned versus impulse purchase behavior. Journal of retailing.

Cohen, J.B., Areni, C. D., (1991). Affect and consumer behaviour, Handbook of Consumer Behaviour, A. Robertson y H. Kassarjian, Eds., Prentice Hall, Englewood Cliffs, NJ, 183- 240.

Fill, C. (2006). Simply marketing communications. Pearson Education.

Heider, F. (1946). Attitudes and cognitive organization. The Journal of psychology, 21(1), 107-112.

Kamble, A. A. (2014). DMM Model in Celebrity: Brand Advertisements. SCMS Journal of Indian Management, 11(4), 89.

Kempf, D. S., \& Smith, R. E. (1998). Consumer processing of product trial and the influence of prior advertising: a structural modelling approach. Journal of Marketing Research, 35(3), 325-338.

MacKenzie, S. B., Lutz, R. J., \& Belch, G. E. (1986). The role of attitude toward the ad as a mediator of advertising effectiveness: A test of competing explanations. Journal of Marketing Research, 23, 130-143.

Mano, H., \& Oliver, R. L. (1993). Assessing the dimensionality and structure of the consumption experience: evaluation, feeling, and satisfaction. Journal of Consumer Research, 20, 451-466.

Morris, J. D., Woo, C., Geason, J. A., \& Kim, J. (2002). The power of affect: predicting intention. Journal of Advertising Research, 42(3), 7- 17.

Meyers-Levy, J., \& Malaviya, P. (1999). Consumers' processing of persuasive advertisements: An integrative framework of persuasion theories. The Journal of Marketing, 45-60.

Mitchell, A. A., \& Jerry C. O. (1981). Are product attribute beliefs the only mediator of advertising effects on brand attitudes? Journal of Marketing Research, 18 (August), 318-31.

Park, C. W., \& Young, S. M. (1984). The effects of involvement and executional factors of a television commercial on brand attitude formation. na.

Petty, R. E., \& Cacioppo, J. T. (1981). Attitudes and persuasion: classic and contemporary approaches. Dubuque, IA: Wm C. Brown.

Petty, R. E., \& Cacioppo, J. T. (1996). Communication and persuasion: central and peripheral routes to attitude change. Editorial Springer-Verlag, New York.

Piron, F. (1991). Defining impulse purchasing. ACR North American Advances.

Rook, D. W. (1987). The buying impulse. Journal of consumer research, 14(2), 189-199.

Rook, D. W., \& Fisher, R. J. (1995). Normative influences on impulsive buying behavior. Journal of Consumer Research, 22(3), 305-313.

Rook, H., \& Hock, A. (1983). Impulse Buying. Advance in consumer Research, 10, 562-567.

Sicilia, M., Ruiz, S., \& Munuera, J. L. (2005). Effects of interactivity in a web site: The moderating effect of need for cognition. Journal of Advertising, 34(3), 31-44.

Smith, D. C., \& Park, C. W. (1992). The effects of brand extensions on market share and advertising efficiency. Journal of Marketing Research, 29(3), 296-313.

Vakratsas, D., \& Ambler, T. (1999). How advertising works: what do we really know?. The Journal of Marketing, 26-43.

Voss, K. E., Spangenberg, E. R., \& Grohmann, B. (2003). Measuring the hedonic and utilitarian dimensions of consumer attitude. Journal of Marking Research, 40, 310-320.

Weinberg, P., \& Gottwald, W. (1982). Impulsive consumer buying as a result of emotions. Journal of Business Research, 10(1), 43-57.

Zaichkowsky, J. L. (1990). Issues in Measuring Abstract-Constructs. ACR North American Advances.

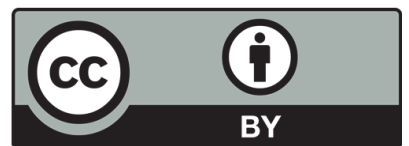

(C) 2017 by the authors; licensee Growing Science, Canada. This is an open access article distributed under the terms and conditions of the Creative Commons Attribution (CC-BY) license (http://creativecommons.org/licenses/by/4.0/). 